\title{
FEATURES OF PORE FORMATION IN WELDED JOINTS OF STEAM LINES IN LONG-TERM OPERATION
}

\author{
V.V. DMITRIK ${ }^{1}$, A.V. GLUSHKO ${ }^{1}$ and S.G. GRIGORENKO ${ }^{2}$ \\ ${ }^{1}$ National Technical University «Kharkov Polytechnic Institute» \\ 21 Frunze Str., 61002, Kharkov, Ukraine. E-mail: omsroot@kpi.kharkov.ua \\ ${ }^{2}$ E.O. Paton Electric Welding Institute, NASU \\ 11 Kazimir Malevich Str., 03680, Kiev, Ukraine. E-mail: office@paton.kiev.ua
}

\begin{abstract}
The paper presents the results of investigation of pore formation in the metal of welded joints in steam lines operating for a long time under creep conditions. Features of pore formation in the regions of welded joint HAZ were revealed that allows improvement of diagnostic assessment of their residual life. Critical threshold of welded joint damage is local density of micropores of $0.8 \mu \mathrm{m}$ and larger size on the level of $1500-1800$ pores per $\mathrm{mm}^{2} .7$ Ref., 7 Figures.
\end{abstract}

Ke y w ord s : steam line welded joints, pores, residual life, diagnostics, damageability, diffusion movement

Diagnostics of residual life of welded joints of TPP steam circuit, which have exhausted their service life, currently is a most important task of thermal power generation in Ukraine.

During long-term operation of welded joints on $\mathrm{Cr}-$ Mo-V heat-resistant pearlitic steels under creep conditions, their damage is due predominantly to pore formation and development. Pore damage in the metal of HAZ, as well as weld and base metal is insufficiently studied, that does not allow diagnosing the residual life of steam line welded joints with sufficient accuracy.

Pore nucleation and development in steam line metal should be regarded as interconnected components of their damage process. The objective of the work was studying the features of the mechanism of pore formation in the metal of welded joints in steam lines from 15Kh1M1F and 12Kh1MF steels in longterm operation. Investigation results allowed lowering the intensity of pore formation and refining the diagnosis of residual life of steam line welded joints [1-7], which are damaged more intensively than the steam line proper.

Welded joint metal structure was studied using microstructural, microprobe and X-ray methods on experimental samples, as well as samples cut out of operating steam lines (Zmiev and Energodar TPPs). Processes of micropore and microcrack formation were examined by electron and optical microscopy.

Micropores nucleate as a result of conjugate effect of diffusion and deformation mechanisms. Diffusion mechanism provides directional displacement of alloying elements, that leads to formation of segregations, and also causes displacement of microdiscontinuities and their coalescence [1]. Deformation mechanism in- cludes the process of dislocation displacement and their retardation, that provides local increase of dislocation density and formation of pore nuclei, the dimensions of which can be approximately $0.1 \mu \mathrm{m}$.

Diffusion-induced movement of alloying elements (chromium and molybdenum) from central zones of $\alpha$-phase grains into their near-boundary zones, as well as movement of reduced elements along grain boundaries leads to formation of segregations, promoting running of carbide reactions of I gr [1]. Movement of alloying elements leads to decrease of strength characteristics of $\alpha$-phase grains, that is confirmed by fragmentation (polygonization) of grains and higher level of their deformation, respectively [2]. It is found that the level of deformation of HAZ regions is much higher than mass deformation of the steam lines equal (at welded joint operating time of more than 250,000 h) to approximately $0.5-0.7 \%$ (Figure 1). It can be shown that deformation of weld metal in welded joints is only slightly different from that of metal of steam lines proper.

In the initial metal of welded joints microdiscontinuities and micropores are chaotically arranged through the body of $\alpha$-phase grains and along their boundaries. Such an arrangement is preserved approximately up to $150,000 \mathrm{~h}$ of steam line operation. During further operation, pore formation occurs with a certain orientation. Pore shape from spherical and ellipsoidal (regular) turns into branched (irregular) during their development. Then the merged pores develop into a crack (Figure 2). Creep cracks have a zigzag shape and develop after welded joints have operated for more than $270,000 \mathrm{~h}$, predominantly in the brittle mode. Pore formation essentially depends on welded joint structure [7]. 


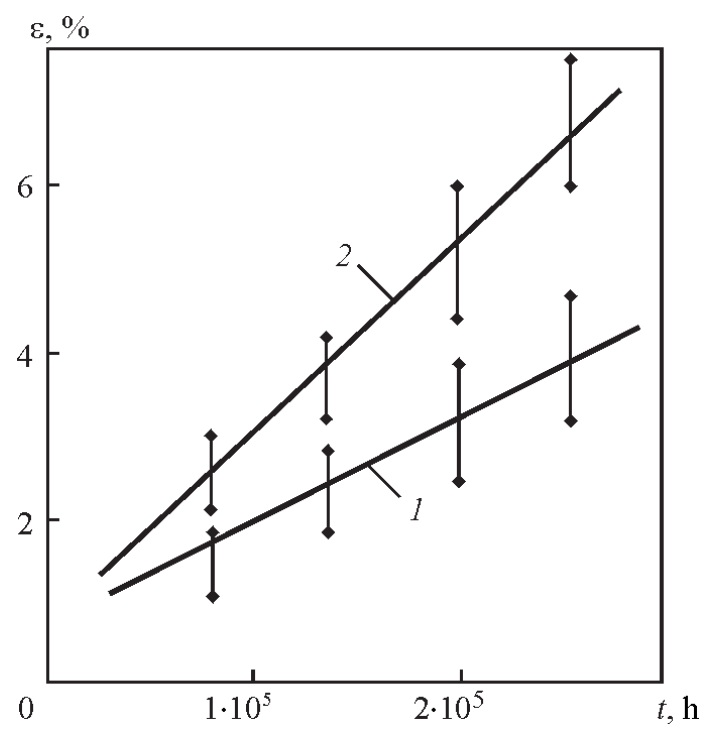

Figure 1. Dependence of relative deformation of metal of 12Kh1MF steel welded joints on its operating time: $1-$ HAZ overheated region; 2 - incomplete recrystallization region

To refine the diagnosis of welded joint residual life, it is rational to determine pore density in those regions of welded joint HAZ, where the greatest structural inhomogeneity is noted, for instance, in incomplete recrystallization region, where new products of austenite decomposition are globular pearlite [6].

Pore formation occurs predominantly along the boundaries of $\alpha$-phase grains and depends on the following: grain boundary location relative to working stresses; structure of grain boundaries (boundaries between two and three grains); and presence of second phase precipitates along the grain boundaries. Pore formation can be regarded as an effect of vacancy condensation due to the degree of plastic deformation, that leads to local oversaturation of grain boundaries with vacancies and formation of microdiscontinuities $[4,6]$. Their formation under creep conditions is provided by development of inner slipping and sliding along the boundaries of $\alpha$-phase grains. This is the

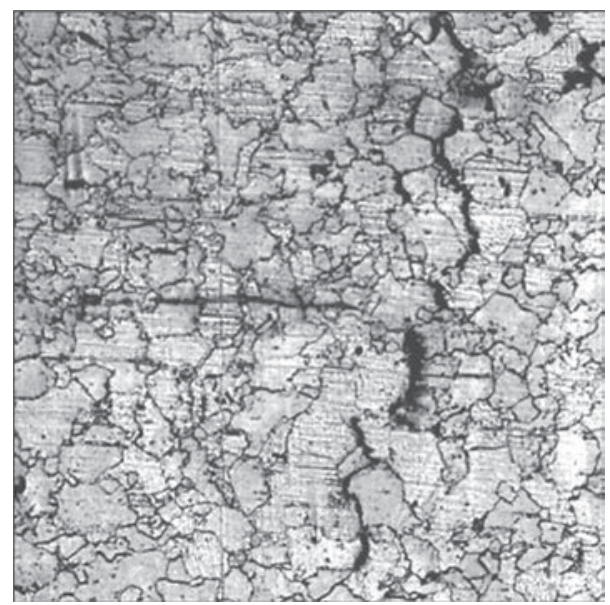

Figure 2. Microsection $(\times 500)$ of welded joint metal of $12 \mathrm{Kh} 1 \mathrm{MF}$ steam line with creep damage after operating time of $280,000 \mathrm{~h}$ at $545-565^{\circ} \mathrm{C}$

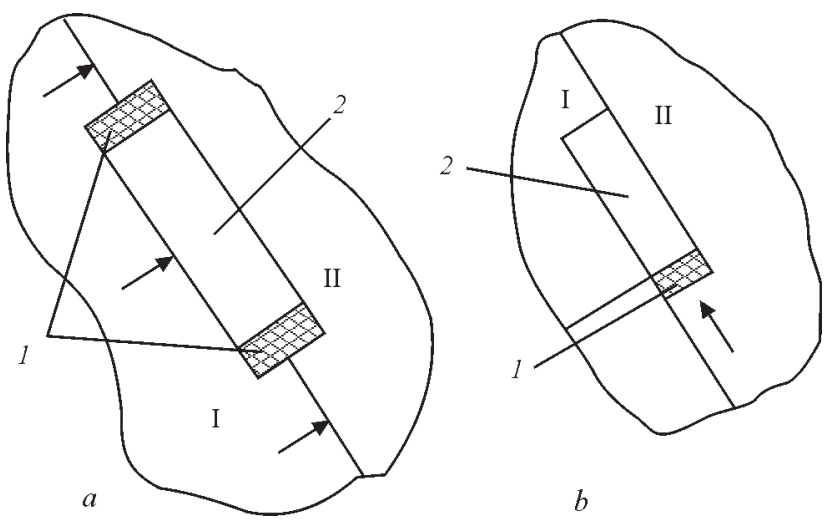

Figure 3. Schematic of micropore nucleus formation: $a-$ formation of cavity 1 on edges of second phase precipitates $2 ; b-$ sliding along the boundary at precipitate 2 leading to formation of micropore nucleus 1; I, II — grains separated by boundary

most intensive in the locations of coagulating second phase precipitates [2].

Sliding along the boundaries of $\alpha$-phase grains in locations of boundary interaction with a coagulating precipitate leads to opening up of the cavity, developing into a nucleating micropore (Figure 3). Further development of pore formation is characterized by certain stages and depends on the structure and conditions of steam line operation (Figure 4).

Under creep conditions (operating time of welded joints of more than 250,000-280,000 h) pore formation through $\alpha$-phase grain body is of chaotic nature. However, pore arrangement along the grain boundaries has certain peculiarities. Micropores form:

- on boundaries normal to tensile stresses, in the points of location of coagulating precipitates of second phases (predominantly, $\mathrm{M}_{23} \mathrm{C}_{6}$ ) — about $70 \%$;

- at the junction of three grains without second phase precipitates - $20 \%$ (Figure 5);

- at the junction of two grains - $10 \%$.

Micropore formation leads to lowering of metal ductility, and is associated with presence of residual deformation. For instance, at mass deformation of welded joint metal of $0.6 \%$, deformation of metal in HAZ incomplete recrystallization region can be equal to 4-6\% (operating time of 280,000 h) that is close to the data of Khromchenko (6-8\%, operating time of 250,000 h) [4].

Note that Khromchenko calls the region of HAZ incomplete recrystallization a «soft interlayer», although its hardness in welded joints of the considered steels $15 \mathrm{Kh} 1 \mathrm{M} 1 \mathrm{~F}$ and $12 \mathrm{Kh} 1 \mathrm{MF}$ can be not less than that of other HAZ regions. Incomplete recrystallization region is characterized by the highest oversaturation with vacancies, compared to other welded joint regions. Such oversaturation is due to self-diffusion of chromium and molybdenum from central zones of $\alpha$-phase grains into near-boundary regions and formation of segregations, as well as diffusion of vacancies and generation of vacancy fluctuations [6]. Fluctua- 


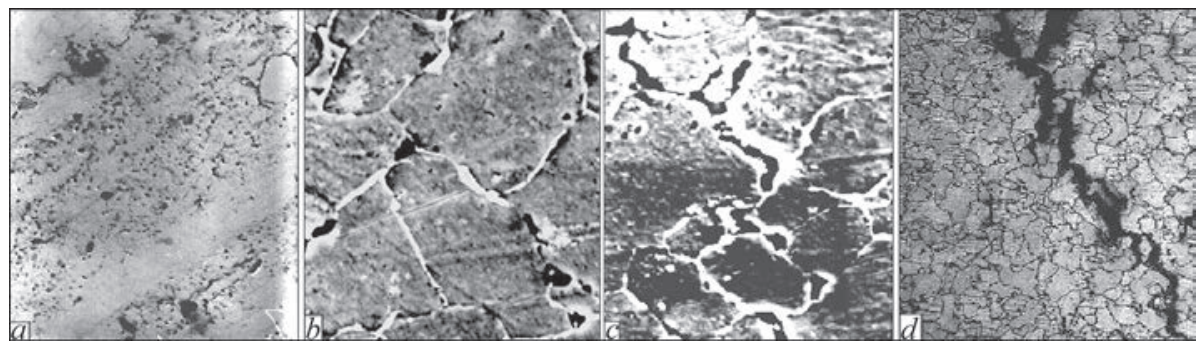

Figure 4. Sequence of pore development in welded joints of 12Kh1MF steel: $a$ - pore nuclei of $0.1-0.3 \mu$ m diameter $(\times 5000)$; $b-$ separate pores of $1-4 \mu \mathrm{m}$ diameter along grain boundaries $(\times 2500)$; $c$ — pores at the stage of coalescence into microcracks $(\times 2500)$; $d$ - creep crack $(\times 500)$; reduction $2 / 3$

tions tend to increase during welded joint operating time of more than $250,000 \mathrm{~h}$. Greenwood's suggestion that pores on grain boundaries under creep conditions should be regarded as the effect of condensation of vacancies, the excess of which relative to the equilibrium concentration is due to plastic deformation, is confirmed [5]. It is found that the number of micropores is increased at increase of plastic deformation. Pore formation is promoted by reduction of the energy of grain boundaries at elimination of part of their surface, that can be regarded as the initial period of recrystallization. The connection between oversaturation with vacancies $\left(\Delta / c_{0}\right)$ and radius $r$ of growing nucleus during diffusion-induced nucleation of a pore was established by Geguzin [5]:

$$
r=2 \gamma V / k T\left(\Delta / c_{0}\right) \text {, }
$$

where $\gamma$ is the surface energy; $V=b^{2}$ is the atomic volume; $\Delta=c_{1}-c_{0}$ is the change of vacancy concentration; $c_{1}$ is the established concentration of vacancies; $c_{0}$ is the equilibrium concentration of vacancies; $k$ is the Boltzmann constant; $T$ is the temperature.

It can be assumed that vacancy concentration in welded joint metal (more than 250,000 h operating time) is 4 to 8 times higher than the equilibrium one.

Considering $b=3.10^{-3} \mathrm{~cm}$ and $\gamma=500 \mathrm{erg} / \mathrm{cm}^{2}$, we will obtain for temperature of $545{ }^{\circ} \mathrm{C}$ the size of pore nucleus including approximately $10^{7}-10^{9}$ vacancies. At further operation under the conditions of working stresses and temperatures, as well as the influence of additional factors (overheating, start/stop of the pipeline, local increase of stresses, etc.) the extent of oversaturation by vacancies can rise by approximately $30-40 \%$.

Respective tensile stresses are induced near the coagulating precipitates, where the dislocations accumulate. Dislocation accumulation is noted at electron microscopy studies of thin foils from samples of welded joints with operating time longer than 270,000 h. This is confirmed by formation of a polygonal structure of $\alpha$-phase grains, i.e. their fragmentation (Figure 6). In the structure of $\alpha$-phase crystals under creep conditions slipping occurs in the direction of the diagonals of cubic lattice $<111>$ in the set of dodecahedral planes $\{110\}$. After welded joints operating for more than $250,000 \mathrm{~h}$, slipping occurs first in planes $\{112\}$, and then also in planes $\{123\}$. Slipping along grain boundaries, depending on precipitate location, generates tensile and compressive stresses, respectively (see Figure 3). Long-acting tensile stresses lead to cavity opening. Micropore nucleation is also related to formation of sub-boundaries near coagulating precipitates.

Known models of pore formation did not allow for presence of coagulating precipitates along the grain boundaries. Note that the sliding speed, required for micropore formation in long-operated welded joints, can be different. Speed depends on arrangement of grain boundaries, their structure, presence of coagulating precipitates of second phases on them and their coagulation intensity. Length of precipitates located along the grain boundaries can be equal to $1-5 \mu \mathrm{m}$ at welded joint operating time longer than 280,000 h. It is established that the quantity of pores forming on grain boundaries depends on their deformation.

For instance, in the metal of incomplete recrystallization region of welded joint HAZ in 15Kh1M1F steel at its deformation of 5-7\%, averaged density of pores of $2-8 \mu \mathrm{m}$ size per $1 \mathrm{~mm}^{2}$ was equal to 7.2 pcs. Deformation of HAZ regions essentially depends on their structure. In the presence of new products of austenite decomposition in the form of globularized pearlite in the structure of incomplete recrystallization region, its deformation can be equal to $5-7 \%$, if they have the form of sorbite it can be $1-2 \%$, in case of troostite it can be about $1 \%$ at mass deformation of

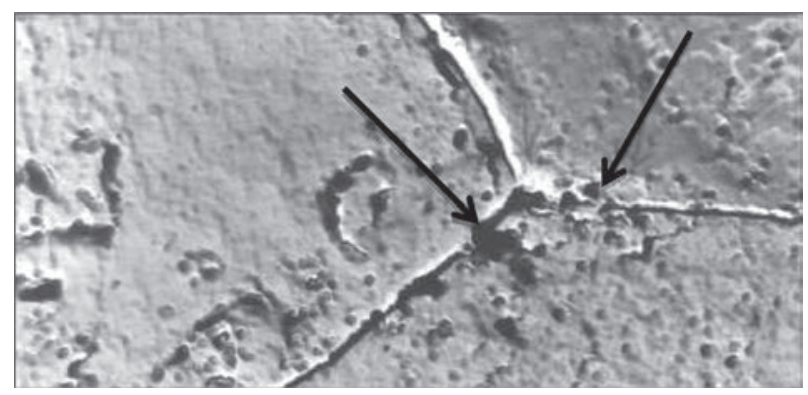

Figure 5. Microsection $(\times 14000)$ of metal of incomplete recrystallization region in HAZ of $12 \mathrm{Kh} 1 \mathrm{MF}$ steel welded joint showing pore nucleation along the junction of three grains (arrows) at operating time of $275,637 \mathrm{~h}$ 


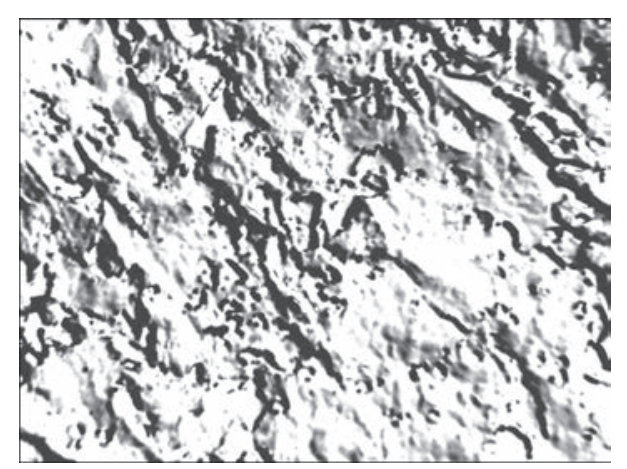

Figure 6. Fragmented structure $(\times 6000)$ of incomplete recrystallization region in HAZ of $15 \mathrm{Kh} 1 \mathrm{M} 1 \mathrm{~F}$ steel welded joint at operating time of $276,000 \mathrm{~h}$

welded joints of about $0.7 \%$. Pore density, depending on operating time of welded joints with the respective structure of new products of austenite decomposition, was distributed as follows (Figure 7).

Obtained results show that the density of micropores of more than $0.8 \mu \mathrm{m}$ size, equal to approximately $1500-1800$ pcs per $\mathrm{mm}^{2}$, can be regarded as critical. Further increase of pore density leads to their accelerated coalescence and formation of creep cracks. Such cracks develop, predominantly, in the brittle mode, that is promoted by presence of coagulating precipitates along the boundaries of $\alpha$-phase grains and of grain-boundary segregations.

Quantity of pores at constantly applied tensile stresses depends on the interaction of inner slipping and sliding, that is initially provided by self-diffusion of chromium and molybdenum, as well as diffusion of vacancies. Their retardation, i.e. lowering of intensity, improves the structure stability under creep conditions.

Sliding can be regarded as the effect of relative displacement of local regions of grain boundaries. Nucleation of microdiscontinuities at the precipitates is related to violation of coherence of precipitates and $\alpha$-phase grains, that is noted at precipitate coagulation. Increase of stability of metal structure in welded joints operating for a long time under creep conditions, essentially reduces the intensity of pore formation.

\section{Conclusions}

1. It is found that pore formation is the most intensive in the region of incomplete recrystallization of welded joint HAZ, where new products of austenite decomposition are globularized pearlite.

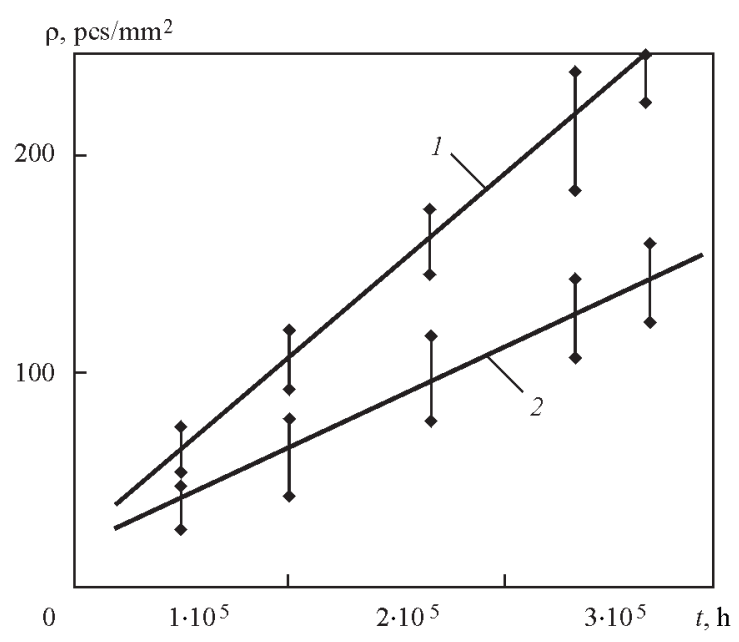

Figure 7. Dependence of density $\rho$ of creep pore with longitudinal size of $0.5-1.1 \mu \mathrm{m}$ formed in incomplete recrystallization region of HAZ of $12 \mathrm{Kh} 1 \mathrm{MF}$ steel welded joint on its operating time $t$ in the presence of new products of austenite decomposition in the form of globularized pearlite (1) and sorbite (2) at operating time of $276,000 \mathrm{~h}$

2. It is established that at damage of welded joints in steam lines in long-term operation under creep conditions, density of micropores of $0.8 \mu \mathrm{m}$ and greater size, equal to $1500-1800$ pes per $\mathrm{mm}^{2}$, can be regarded as critical.

3. It is shown that the quantity of micropores in the regions of HAZ metal of steam line welded joints depends on the region deformations and is the largest in incomplete recrystallization region, where new products of austenite decomposition are globularized pearlite.

1. Dmitrik, V.V., Baumer, V.N. (2007) Carbide phases and damageability of welded joints in long-term service. Metallofizika, Nov. Tekhnologii, 2(7), 937-947.

2. Dmitrik, V.V., Sobol, O.V., Pogrebnoj, M.A. et al. (2015) Peculiarities of degradation of metal in welded joints of steam pipelines. The Paton Welding J., 7, 10-15.

3. Trubachev, V.M., Kamenskaya, N.I. (2012) Methods of evaluation of microdamageability of metal in long-term service steam pipelines of thermal power station. Metallovedenie $i$ Termich. Obrab. Metallov, 8, 49-54.

4. Khromchenko, F.A. (2002) Service life of welded joints of steam pipelines. Moscow: Mashinostroenie.

5. Rozenberg, V.M. (1967) Creep of metals. Moscow: Metallurgiya.

6. Dmitrik, V.V., Sirenko, T.A., Bartash, S.M. et al. (2015) Refinement of metal damageability mechanism of welded joints in long-term service steam pipelines. Vost.-Evrop. Zhurnal Pered. Tekhnologij, 6, 13-18.

7. Berezina, T.G. (1986) Structural method for definition of residual life of parts in long-term service steam pipelines. Teploenergetika, 3, 53-56. 